\title{
Can Fundamentals Explain Cross-Country Correlations of Asset Returns?
}

\author{
Fernando Restoy and Rosa Rodríguez
}

Banco de España, Madrid; Universidad Carlos III, Madrid

\begin{abstract}
Previous studies show that existing correlations between national returns are higher than correlations between the national growth rates of fundamental variables. This paper examines the ability of intertemporal asset pricing models to explain cross-country correlations of national returns. We find that when capital markets are assumed to be fully integrated, a simple intertemporal general equilibrium model is able to explain the observed co-variability of domestic asset returns but generates too little variability in those returns. Results improve considerably if a less restrictive version is employed. In that setting, both domestic variability and cross-country co-variability of returns are consistent with capital market integration. JEL. no. G12, G15, E44
\end{abstract}

Keywords: Asset pricing models; cross-country correlations

\section{Introduction}

The interaction of financial asset prices and real activity has recently become an important topic in macroeconomic research. A considerable body of economic and financial literature has attempted to explain some stylized facts such as the predictability and the excess volatility of asset returns and the spread between equity and risk-free returns (see e.g. Campbell 2000, Cochrane 2000 and Rodríguez et al. 2002, among others). In the last few years, however, the empirical literature has documented another important regularity: existing correlations between national returns are higher than correlations between the national growth rates of fundamental variables

Remark: Rosa Rodríguez acknowledges financial support provided by a Ministerio de Ciencia y Tecnología grant SEC2003-06457. Please address correspondence to Fernando Restoy, Banco de España. Servicio de Estudios. c/ Alcalá-48. 28014 Madrid. Spain; e-mail: FRESTOY@bde.es 
such as aggregate output, consumption or dividends (Ammer and Mei 1996; Dumas et al. 2003).

This relatively high cross-country correlation of asset returns might suggest that participants in domestic stock markets tend to overreact to international news. To some extent this is at odds with the extensive literature that illustrates the "domestic bias" in asset portfolios (French and Poterba 1991; Cooper and Kaplanis 1994; Tesar and Werner 1995). It is not easy to conceive agents that despite showing a great preference for domestic assets, overestimate the impact of international developments on the profitability of domestic firms, to the point of generating "overintegration" of domestic markets.

In a recent paper Dumas et al. (2003) provide a possible explanation for the puzzle. If domestic markets were integrated, stock prices should be formed in all countries by applying a single discount factor (pricing kernel) to the payoff structure of securities in all countries. Following a general Lucas-type equilibrium approach they find that by applying a single pricing kernel, derived from an international asset pricing model, to domestic outputs one can derive cross-country correlations of equilibrium asset returns which may match the ones observed. Unfortunately, the hypothesis of full-integration of international stock markets is rejected by the data in their simple general equilibrium setup. However, given the limited importance of dividend income on countries' GDP, and the moderate but not insignificant openness of domestic stock markets, the assumption that domestic dividends are equal to domestic output is very strong. It is therefore possible that rejection of the full integration hypothesis is the consequence of employing a very restrictive asset pricing model.

In this paper we explore the hypothesis of international stock market integration under different intertemporal asset pricing models. In particular we focus on whether it is possible to obtain more support to the hypothesis in a partial equilibrium setup in which dividends in a specific country are not supposed to be equal to output in the same country.

We use the approach developed by Restoy and Weil (1998), to obtain approximate closed-form solutions that relate returns with macroeconomic fundamentals in both a partial equilibrium and a simple general equilibrium framework. By applying the Generalized Method of Moments (GMM), we are then able to estimate the preference parameters that minimize deviations between observed and model-generated volatility and cross-country covariability of stock returns. 
The remainder of the paper is organized as follows. Section 2 describes the framework used to derive approximate equilibrium returns. Section 3 reports the empirical approach. The results are presented in Section 4 . Finally, Section 5 contains some concluding remarks.

\section{The Models}

Given that the objective is to study cross-country correlations we must specify an international asset pricing model. It is useful, however, to introduce, first, a single-country economy.

\subsection{The Closed-Economy}

Suppose an infinitely lived representative agent economy. The representative agent is endowed with the aggregate wealth of the economy and has Generalized Isoelastic Preferences (GIP) as defined by Epstein and Zin (1989) and Weil (1989). These preferences are characterized by a constant elasticity of substitution $(1 / \rho)$ and also a constant, but possibly different, coefficient of relative risk aversion $(\gamma)$.

The first-order conditions yield an Euler equation that incorporates a stochastic discount factor for asset returns that depends on both aggregate consumption and the return on the wealth portfolio. Since those two variables should be linked in equilibrium it is, in principle, possible to use the consumption function to eliminate one or another variable from the asset pricing expressions. The consumption function cannot in general be derived analytically. To circumvent this difficulty Campbell (1993) and Restoy and Weil (1998) loglinearize both the budget constraint and the Euler equation, in order to provide an approximate expression for the consumption-wealth ratio. While Campbell (1993) expresses that ratio as a function of aggregate asset returns, Restoy and Weil (1998) employ an equilibrium perspective and present an expression of the consumption wealth ratio that depends only on the conditional distribution of the consumption (endowment) process.

Once the consumption-wealth ratio is derived, it is possible to obtain approximate closed-form solutions for asset returns as a function of its payoff structure and aggregate consumption. In particular, assuming homoscedasticity of the consumption growth process, Restoy and Weil (1998) show that the rate of return on the market portfolio can be written 
as,

$$
\begin{gathered}
r_{m, t+1}=\psi_{m}+\rho x_{t+1}+S_{t+1} \sum_{j=0}^{\infty} \delta^{j} d_{m, t+j+1} \\
-\rho S_{t+1} \sum_{j=0}^{\infty} \delta^{j} x_{t+j+1}
\end{gathered}
$$

where $r_{m, t+1}$ is the return on the aggregate portfolio, $x_{t+1}$ is the growth rate of aggregate consumption, $d_{m, t \times 1}$ the growth rate of dividends paid off between dates $t$ and $t+1, \delta$ is equal to one minus the unconditional expectation of the consumption-wealth ratio, $\psi_{m}$ is a constant and $S_{t+1}$ is the surprise operator defined as $S_{t+1} x_{t+1}=E_{t+1} x_{t+1}-E_{t} x_{t+1}$.

The interpretation of (1) was given by Restoy and Weil (1998). Good news about future dividends increase the level of returns. Similarly, news that future consumption will be lower also increase current returns because they signal that the discount factor for future payoffs will be lower and, therefore, future prices will be higher. Naturally, the more averse the consumers are to intertemporal substitution (the larger $\rho$ ), the more sensitive equilibrium returns are to changes in consumption growth.

Under a general equilibrium perspective where output is equal to consumption and dividends, the return on the market portfolio can be written as,

$$
r_{m, t+1}=\mu+\rho y_{t+1}+(1-\rho) S_{t+1} \sum_{j=0}^{\infty} \delta^{j} y_{t+j+1}
$$

where $y_{t+1}$ is the growth rate of aggregate output.

\subsection{Multicountry Economy}

The extension of the above model to a multicountry setting is straight forward. Assume that there exist $K$ countries $(k=1,2, \ldots, K)$ and international capital markets are perfectly integrated. We can then assume a representative consumer who will now be endowed with the world wealth. He can invest in $K$ assets (one for each country) that provides a stream of dividends $\left[d_{k, t}, t=1, \ldots, \infty, k=1, \ldots, K\right]$. Where, $d_{k, t}$ represents aggregate dividends of country $k$ in period $t$.

Following the same reasoning than before we can derive expressions for the returns on country $k$ in both a partial and a general equilibrium setting. 
In the partial equilibrium case,

$$
\begin{aligned}
r_{k, t+1}= & \psi_{k}+\rho X_{t+1}+S_{t+1} \sum_{j=0}^{\infty} \delta_{k}^{j} d_{k, t+j+1} \\
& -\rho S_{t+1} \sum_{j=0}^{\infty} \delta_{k}^{j} X_{t+j+1} \quad k=1,2, \ldots, K,
\end{aligned}
$$

where $X_{t+1}$ is the world aggregate consumption growth.

The general equilibrium solution implies in this multicountry setting that domestic output should be equal to domestic dividends although not necessarily to domestic consumption, since countries are supposed to trade with each other. However, aggregate world output should, logically, be equal to aggregate world consumption. ${ }^{1}$ Therefore, in this case,

$$
\begin{aligned}
r_{k, t+1}= & \psi_{k}+\rho Y_{t+1}+S_{t+1} \sum_{j=0}^{\infty} \delta_{k}^{j} y_{k, t+j+1} \\
& \quad-\rho S_{t+1} \sum_{j=0}^{\infty} \delta_{k}^{j} Y_{t+j+1} \quad k=1,2, \ldots, K,
\end{aligned}
$$

where $Y_{t+1}$ denotes aggregate world output growth and $y_{k, t+1}$ is the growth rate of output for country $k$.

\section{Empirical Approach}

Given that the models provide approximate closed-form expressions for equilibrium returns we should now be able to understand the determinants of their cross-country correlations.

As a first exercise, it is useful to compare cross-country correlations of observed returns with those of some relevant macroeconomic variables such as output, consumption and aggregate dividends.

For that purpose, we use quarterly data for the period from 1970:1 to 2002:2 for eight OECD countries: Canada (CA), France (FR), Germany (GE), Italy (IT), Japan (JA), Spain (SP), the United Kingdom (UK) and the United States (US). Aggregate returns and dividend yields for each

\footnotetext{
1 Dumas et al. (2003) assume this exchange economy, where aggregate consumption growth $\left(\Delta x_{t+1}\right)$ is equal to the weighted sum of output growth rates of individual countries $\left(\Delta d_{j, t+1}\right)$.
} 
Table 1a: Unconditional Correlation Matrices, 1970:1-2002:2

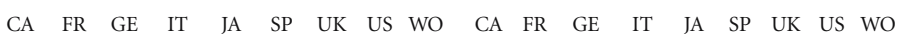

Observed returns

$\begin{array}{llllllllll}\text { Mean (\%) } & 1.28 & 1.62 & 1.39 & 0.49 & 0.69 & 0.75 & 1.43 & 1.48 & 1.53\end{array}$ s.d. $(\%) \quad 8.8111 .6210 .63 \quad 13.3310 .7012 .7010 .41 \quad 8.50 \quad 8.21$

FR $\quad 0.53$

GE $\quad 0.50 \quad 0.67$

$\begin{array}{llll}\text { IT } & 0.43 & 0.62 & 0.52\end{array}$

$\begin{array}{lllll}\text { JA } & 0.45 & 0.40 & 0.39 & 0.39\end{array}$

$\begin{array}{llllll}\text { SP } & 0.45 & 0.51 & 0.54 & 0.57 & 0.48\end{array}$

$\begin{array}{llllllll}\text { UK } & 0.55 & 0.58 & 0.51 & 0.46 & 0.46 & 0.43\end{array}$

$\begin{array}{llllllll}\text { US } & 0.78 & 0.64 & 0.58 & 0.45 & 0.52 & 0.52 & 0.69\end{array}$

$\begin{array}{lllllllll}\text { WO } & 0.78 & 0.71 & 0.67 & 0.56 & 0.71 & 0.62 & 0.78 & 0.92\end{array}$

Mean pairwise correlations 0.57

Dividend growth

$\begin{array}{llllllllll}\text { Mean (\%) } & 1.93 & 2.66 & 1.61 & 2.58 & 0.54 & 2.54 & 2.83 & 2.02 & 1.88\end{array}$

$\begin{array}{lllllllllll}\text { s.d. (\%) } & 3.39 & 3.44 & 6.24 & 10.71 & 3.89 & 4.46 & 3.24 & 2.62 & 2.59\end{array}$

FR $\quad 0.11$

GE $\quad 0.06 \quad 0.32$

$\begin{array}{llll}\text { IT } & -0.12 & 0.17 & 0.06\end{array}$

$\begin{array}{lllll}\text { JA } & 0.21 & 0.11 & 0.07 & 0.12\end{array}$

$\begin{array}{llllll}\text { SP } & 0.21 & 0.01 & 0.17 & -0.05 & 0.13\end{array}$

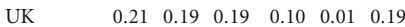

$\begin{array}{llllllll}\text { US } & 0.25 & 0.18 & 0.13 & -0.10 & 0.11 & 0.10 & 0.28\end{array}$

$\begin{array}{lllllllll}\text { WO } & 0.18 & 0.33 & 0.28 & 0.14 & 0.21 & 0.22 & 0.37 & 0.60\end{array}$

Mean pairwise correlations 0.16

\section{Consumption growth}

$\begin{array}{lllllllll}0.41 & 0.42 & 0.26 & 0.55 & 1.00 & 0.49 & 0.60 & 0.46 & 0.38\end{array}$ $\begin{array}{llllllllll}0.88 & 0.75 & 6.15 & 0.69 & 1.71 & 0.75 & 1.16 & 0.71 & 0.70\end{array}$

0.18

$0.14 \quad 0.07$

$\begin{array}{lll}0.17 & 0.21-0.02\end{array}$

$\begin{array}{llll}0.00 & 0.15 & 0.01 & 0.03\end{array}$

$\begin{array}{llllll}0.27 & 0.32 & 0.04 & 0.38 & 0.03\end{array}$

$\begin{array}{lllllll}0.24 & 0.18 & 0.00 & 0.06 & 0.14 & 0.15\end{array}$

$\begin{array}{llllllll}0.35 & 0.24 & 0.00 & -0.04 & 0.22 & 0.14 & 0.23\end{array}$

$\begin{array}{llllllll}0.34 & 0.41 & 0.08 & 0.33 & 0.19 & 0.32 & 0.27 & 0.53\end{array}$

Mean pairwise correlations 0.18

\section{Industrial production growth}

$\begin{array}{lllllllll}0.69 & 0.46 & 0.37 & 0.48 & 0.56 & 0.68 & 0.29 & 0.68 & 0.55\end{array}$

$\begin{array}{lllllllll}1.72 & 1.44 & 1.65 & 2.35 & 2.02 & 1.95 & 1.94 & 1.67 & 1.30\end{array}$

0.45

0.220 .53

$\begin{array}{lll}0.34 & 0.47 & 0.28\end{array}$

$\begin{array}{llll}0.51 & 0.42 & 0.45 & 0.34\end{array}$

$\begin{array}{llllll}0.33 & 0.47 & 0.30 & 0.23 & 0.28\end{array}$

$\begin{array}{lllllll}0.20 & 0.32 & 0.31 & 0.29 & 0.21 & 0.07\end{array}$

$\begin{array}{llllllll}0.73 & 0.45 & 0.35 & 0.35 & 0.49 & 0.21 & 0.36\end{array}$

$\begin{array}{lllllllll}0.71 & 0.66 & 0.62 & 0.56 & 0.77 & 0.34 & 0.49 & 0.87\end{array}$

Mean pairwise correlations 0.42

Note: This table gives the mean, standard deviation and the unconditional correlation matrices of national observed returns, consumption growth, dividends growth and industrial production growth (expressed in percentage quarterly units).

country have been obtained from MSCI (Morgan Stanley Capital International). The source of industrial production, consumption, inflation and the three-month interest rate is the OECD's Main Economic Indicators. We also compute world aggregates of all macro economic variables by using the national weights employed by MSCI to calculate the world portfolio.

Table $1 \mathrm{a}$ and $1 \mathrm{~b}$ report the mean, standard deviation and the unconditional correlation matrices of stock returns and the growth rates of consumption, dividends and industrial production. We provide calculations for the period from 1970 to 2002 period and from 1987 to 2002. This sample split is justified by the possibility that the capital market liberalization in the last two decades could have an impact on the statistics computed.

The mean pairwise correlation of returns is 0.57 , while the cross-country correlations of industrial production growth, consumption growth and dividend growth average $0.42,0.18$ and 0.16 respectively (Table $1 \mathrm{a})$. Therefore, 
Table 1b: Unconditional Correlation Matrices, 1987:1-2002:2

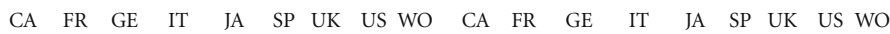

Observed returns

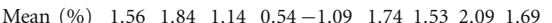

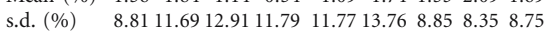

FR $\quad 0.76$

GE $\quad 0.62 \quad 0.83$

$\begin{array}{llll}\text { IT } & 0.60 & 0.74 & 0.71\end{array}$

$\begin{array}{lllll}\text { JA } & 0.50 & 0.50 & 0.42 & 0.45\end{array}$

$\begin{array}{llllll}\text { SP } & 0.68 & 0.76 & 0.71 & 0.75 & 0.55\end{array}$

$\begin{array}{lllllll}\text { UK } & 0.70 & 0.76 & 0.66 & 0.63 & 0.55 & 0.72\end{array}$

$\begin{array}{llllllll}\text { US } & 0.81 & 0.80 & 0.69 & 0.62 & 0.58 & 0.73 & 0.84\end{array}$

$\begin{array}{llllllllll}\text { WO } & & 0.80 & 0.84 & 0.74 & 0.70 & 0.78 & 0.81 & 0.87 & 0.93\end{array}$

Mean pairwise correlations 0.70

Dividend growth

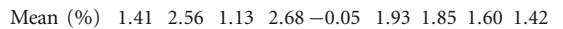
$\begin{array}{llllllllll}\text { s.d. (\%) } & 3.00 & 3.51 & 7.70 & 7.63 & 4.67 & 4.79 & 3.72 & 1.69 & 2.67\end{array}$

FR $\quad 0.01$

$\begin{array}{lll}\text { GE } & 0.12 & 0.39\end{array}$

IT $\quad-0.13 \quad 0.11 \quad 0.00$

$\begin{array}{lllll}\text { JA } & 0.18 & 0.14 & 0.09 & 0.13\end{array}$

$\begin{array}{llllll}\text { SP } & 0.13 & 0.17 & 0.32 & 0.09 & 0.08\end{array}$

$\begin{array}{llllllll}\text { UK } & & 0.03 & 0.13 & 0.19 & 0.18 & -0.04 & 0.25\end{array}$

$\begin{array}{llllllll}\text { US } & 0.19 & 0.27 & 0.22 & 0.02 & 0.20 & 0.20 & 0.43\end{array}$

$\begin{array}{lllllllll}\text { WO } & -0.03 & 0.42 & 0.36 & 0.36 & 0.24 & 0.30 & 0.37 & 0.48\end{array}$

Mean pairwise correlations 0.18
Consumption growth

$\begin{array}{llllllllll}0.38 & 0.37 & -0.02 & 0.46 & 1.03 & 0.62 & 0.70 & 0.51 & 0.28\end{array}$ $\begin{array}{llllllllll}0.70 & 0.59 & 4.04 & 0.63 & 1.97 & 0.67 & 0.74 & 0.49 & 0.81\end{array}$

0.14

0.190 .20

$\begin{array}{lll}0.26 & 0.19 & 0.02\end{array}$

$\begin{array}{lll}-0.22 & 0.12-0.09-0.06\end{array}$

$\begin{array}{llll}0.25 & 0.27 & 0.04 & 0.65-0.03\end{array}$

$\begin{array}{lllllll}0.37 & 0.13 & 0.11 & 0.13 & -0.10 & 0.12\end{array}$

$\begin{array}{llllllll}0.41 & 0.11 & 0.10 & 0.05 & 0.02 & 0.17 & 0.26\end{array}$

$\begin{array}{llllllll}0.28 & 0.26 & 0.11 & 0.43 & -0.01 & 0.36 & 0.07 & 0.36\end{array}$

Mean pairwise correlations 0.16

Industrial production growth

$\begin{array}{lllllllll}0.64 & 0.45 & 0.39 & 0.36 & 0.25 & 0.49 & 0.23 & 0.71 & 0.50\end{array}$ $\begin{array}{llllllllll}1.36 & 1.02 & 1.49 & 1.44 & 1.86 & 1.45 & 0.91 & 0.99 & 0.88\end{array}$

0.28

$\begin{array}{rr}-0.09 & 0.60\end{array}$

$\begin{array}{lll}0.38 & 0.59 & 0.38\end{array}$

$\begin{array}{llll}0.38 & 0.24 & 0.31 & 0.27\end{array}$

$\begin{array}{lllll}0.30 & 0.57 & 0.40 & 0.42 & 0.30\end{array}$

$\begin{array}{lllllll}0.38 & 0.37 & 0.24 & 0.36 & 0.35 & 0.39\end{array}$

$\begin{array}{llllllll}0.73 & 0.33 & 0.09 & 0.36 & 0.35 & 0.37 & 0.49\end{array}$

$\begin{array}{lllllllll}0.62 & 0.60 & 0.52 & 0.59 & 0.77 & 0.55 & 0.59 & 0.76\end{array}$

Mean pairwise correlations 0.42

Note: This table gives the mean, standard deviation and the unconditional correlation matrices of national observed returns, consumption growth, dividends growth and industrial production growth (expressed in percentage quarterly units).

correlations of returns are, generally, larger than correlations of fundamentals. A similar path is found for the second part of the sample; in this case the gap between cross-country correlations of returns and cross-country correlations of fundamentals is even larger (Table 1b).

In order to check whether this apparent "excess correlation" of returns is compatible with equilibrium pricing in an integrated capital market setting we need to generate approximate equilibrium returns according to equations (1)-(4). We work in a multivariate framework that involves two steps. In the first step, we generate innovations of fundamentals for each country and for the world market. In the second step, we estimate and test the model:

Step 1 . We define a set of nine four-element vectors $z_{k} ;(k=1, \ldots, 9)$ whose components are: the real stock return, the growth rate of output or the growth rate of consumption, the dividend growth and the (detrended) 
short-term interest rate. We then assume that the vector $z_{k, t+1}$ follows a firstorder $\operatorname{VAR}^{2}$ :

$$
z_{k, t+1}=\alpha_{k}+A_{k} z_{k, t}+w_{k, t+1} .
$$

Next we define a four-element selection vector $i 2$, whose second element is 1 and the rest are all 0 . Since the first-order VAR generates a simple multiperiod forecast of future growth rates of aggregate output, we can obtain innovations in output of country $k$ by computing,

$$
S_{t+1} \sum_{j=0}^{\infty} \delta^{j} y_{k, t+1+j}=i 2^{\prime} \sum_{j=0}^{\infty} \delta^{j} A_{k}^{j} w_{k, t+1}=i 2^{\prime}\left(I-\delta A_{k}\right)^{-1} w_{k, t+1} .
$$

We can similarly generate multiperiod forecasts of any fundamental variable by using the selection vector that corresponds to the position of the variable in the vector $z_{k}$. For the empirical exercises we use a value of $\delta$ equal to $0.95 .{ }^{3}$

Step 2. Once surprises for fundamental variables have been generated we can exploit empirically expressions (3) and (4). In particular, we will estimate $\rho$ by GMM and test the integrated capital market model. For the partial equilibrium expression (3) we need to employ data of consumption and dividends. In the general equilibrium expression (4) we just need to use domestic and aggregate output since the former should be equal to domestic dividends and the latter is equal to aggregate consumption. ${ }^{4}$

For the sake of comparison, we also test a segmented model in which stocks are priced in each country according to the first order conditions of a representative domestic agent endowed with national wealth. For that purpose we exploit (2) for each country, where $r_{m, t+1}$ and $y_{t+1}$ refers to domestic aggregate returns and output respectively. For that exercise we estimate a different $\rho$ in each country by matching the variance of modelgenerated returns with that of actual returns.

\footnotetext{
2 The assumption that the VAR is first-order is not restrictive, since a higher-order VAR can always be expressed as a first-order form in the manner discussed by Campbell and Shiller (1988). However, the Schwarz (1978) criterion yields always a first-order VAR system.

3 Results are not sensitive to variations in $\delta$ within a plausible range.

4 Alternatively we could have used other combinations of data such as domestic output and aggregate consumption. But then we would have not made full use of the general equilibrium conditions and results would not be directly comparable with those of Dumas et al. (2003).
} 


\section{Empirical Results}

\subsection{Segmented Model}

Table 2 reports estimated values of $\rho$ that match the volatility for each country observed and model-generated returns when markets are supposed to be segmented ${ }^{5}$ and the equilibrium assumption (consumption $=$ dividends $=$ output) is ignored. We find positive and significant estimates of the inverse of the elasticity of intertemporal substitution. The point estimates range form 5 to 42 .

Table 2: Values of the Inverse of the Elasticity of Intertemporal Substitution in a Segmented Context, 1970:4-2002:2

\begin{tabular}{|c|c|c|c|c|c|c|c|c|}
\hline & CA & FR & GE & IT & JA & SP & UK & US \\
\hline $\begin{array}{l}\text { General } \\
\text { equilibrium }\end{array}$ & $\begin{array}{l}5.479 \\
(0.53)\end{array}$ & $\begin{array}{c}14.986 \\
(1.32)\end{array}$ & $\begin{array}{l}15.37 \\
(-1.7)\end{array}$ & $\begin{array}{c}16.844 \\
(1.46)\end{array}$ & $\begin{array}{l}5.326 \\
(0.55)\end{array}$ & $\begin{array}{c}23.942 \\
(2.46)\end{array}$ & $\begin{array}{l}42.159 \\
(6.46)\end{array}$ & $\begin{array}{r}5.808 \\
(0.63)\end{array}$ \\
\hline
\end{tabular}

Note: This table reports the values of $\rho$ estimated from each model using Hansen's (1982) Generalized Method of Moments. The values match the volatility of observed returns and model-generated returns. Standard errors are in parentheses. General equilibrium values are obtained from (2).

Once estimates of $\rho$ are available across countries, we can generate cross-country correlation matrices of returns. We can then check the crosscountry correlations of model-generated returns are and compare them with the correlation of observed returns.

Table 3 presents the correlation matrix of generated returns of the fully segmented model using the estimated values of the inverse of the elasticity of substitution.

If we compare the correlation matrix of observed returns and the correlation matrix of model-generated returns, we observe that in all cases the pairwise correlations of observed returns are larger than corresponding pairwise correlations of generated returns. That confirms the results of $\mathrm{Du}$ mas et al. (2003) obtained with monthly data from 1970 to 1996. Moreover,

5 Note that the constant $\psi_{k}$ is not necessarily to be estimated because correlations do not change by a constant. In general, the first moment of returns depends on other preference parameters, such as risk aversion, but second moments only depend on $\rho$. Since we are only using second moments as moment conditions, we do not show other parameter in the GMM procedure. 
Table 3: Correlation of Generated Returns by a Segmented Market Model, 1970:1-2002:2

\begin{tabular}{|c|c|c|c|c|c|c|c|c|}
\hline & CA & FR & GE & IT & JA & SP & UK & US \\
\hline CA & 1.00 & & & & & & & \\
\hline FR & 0.26 & & & & & & & \\
\hline GE & -0.13 & 0.26 & & & & & & \\
\hline IT & 0.28 & 0.31 & 0.00 & & & & & \\
\hline JA & 0.11 & 0.12 & 0.17 & 0.09 & & & & \\
\hline SP & 0.09 & 0.11 & 0.03 & 0.13 & 0.16 & & & \\
\hline UK & -0.02 & 0.09 & 0.17 & -0.08 & -0.03 & 0.11 & & \\
\hline \multirow[t]{2}{*}{ US } & 0.34 & 0.16 & 0.15 & 0.01 & 0.37 & 0.24 & 0.09 & \\
\hline & \multicolumn{8}{|c|}{ Mean pairwise correlations 0.16} \\
\hline
\end{tabular}

Note: This table reports the unconditional correlation matrices of national generated returns by segmented capital market model.

in only two cases the correlations of generated returns are larger than the correlation of outputs. Therefore, the fully segmented model predicts too little cross-country correlations of asset returns.

\subsection{Integrated Model}

We estimate the fully integrated market model, using both the partial equilibrium (3) and the general equilibrium (4) specifications. We report results for both the 1970-2002 and the 1987-2002 subperiod.

Table 4 presents the values of $\rho$ found for the fully integrated market model, using both the partial equilibrium and the general equilibrium specification. Panel A presents the estimated values of $\rho$ obtained by matching the volatility of observed returns with that of model-generated returns. Panels $\mathrm{B}$ and $\mathrm{C}$ present results corresponding to the case in which cross-country covariances and correlations are the moments to be matched. Finally Panel D provides results for the GMM estimation in which all components of the variance-covariance matrix of domestic asset returns are used as moment equations. The p-values of the overidentifying restrictions of the models are also presented for each case. ${ }^{6}$

The econometric analysis provides significant and in general reasonable estimates of the representative agent's preference parameters in all cases.

6 We have eight variances and 28 covariances or correlations to match. When using the whole variance-covariance matrix we have therefore 36 moments to match. 
Table 4: GMM Estimation Results for the Fully Integrated Market Model

\begin{tabular}{|c|c|c|c|c|}
\hline \multicolumn{3}{|c|}{ 1970:4-2002:2 } & \multicolumn{2}{|c|}{ 1987:1-2002:2 } \\
\hline & General equilibrium & Partial equilibrium & General equilibrium & Partial equilibrium \\
\hline \multicolumn{5}{|c|}{ Panel A: Matching variances } \\
\hline$\rho$ & $\begin{array}{c}4.97 \\
(0.46)\end{array}$ & $\begin{array}{l}15.68 \\
(2.30)\end{array}$ & $\begin{array}{c}5.83 \\
(1.29)\end{array}$ & $\begin{array}{l}11.94 \\
(6.19)\end{array}$ \\
\hline$\chi^{2}$ & $\begin{array}{l}14.68 \\
(0.04)\end{array}$ & $\begin{array}{l}14.83 \\
(0.04)\end{array}$ & $\begin{array}{l}13.63 \\
(0.06)\end{array}$ & $\begin{array}{l}14.33 \\
(0.05)\end{array}$ \\
\hline \multicolumn{5}{|c|}{ Panel B: Matching covariances } \\
\hline$\rho$ & $\begin{array}{c}3.60 \\
(0.38)\end{array}$ & $\begin{array}{l}11.61 \\
(2.03)\end{array}$ & $\begin{array}{c}4.54 \\
(0.96)\end{array}$ & $\begin{array}{l}11.85 \\
(3.78)\end{array}$ \\
\hline$\chi^{2}$ & $\begin{array}{l}41.67 \\
(0.03)\end{array}$ & $\begin{array}{l}32.00 \\
(0.23)\end{array}$ & $\begin{array}{l}32.96 \\
(0.19)\end{array}$ & $\begin{array}{l}33.55 \\
(0.18)\end{array}$ \\
\hline \multicolumn{5}{|c|}{ Panel C: Matching correlations } \\
\hline$\rho$ & $\begin{array}{c}1.36 \\
(0.06)\end{array}$ & $\begin{array}{c}8.11 \\
(0.52)\end{array}$ & $\begin{array}{c}2.16 \\
(0.09)\end{array}$ & $\begin{array}{l}12.04 \\
(0.41)\end{array}$ \\
\hline$\chi^{2}$ & $\begin{array}{l}73.94 \\
(0.002)\end{array}$ & $\begin{array}{l}56.49 \\
(0.08)\end{array}$ & $\begin{array}{l}50.84 \\
(0.19)\end{array}$ & $\begin{array}{l}46.73 \\
(0.32)\end{array}$ \\
\hline \multicolumn{5}{|c|}{ Panel D: Matching variances-covariances } \\
\hline$\rho$ & $\begin{array}{c}3.95 \\
(0.34)\end{array}$ & $\begin{array}{l}12.54 \\
(1.96)\end{array}$ & $\begin{array}{c}6.17 \\
(0.68)\end{array}$ & $\begin{array}{l}14.56 \\
(2.74)\end{array}$ \\
\hline$\chi^{2}$ & $\begin{array}{l}93.66 \\
(0.000)\end{array}$ & $\begin{array}{l}73.08 \\
(0.000)\end{array}$ & $\begin{array}{l}52.05 \\
(0.03)\end{array}$ & $\begin{array}{l}48.76 \\
(0.07)\end{array}$ \\
\hline
\end{tabular}

Note: This table reports the values of $\rho$ estimated for each model using Hansen's (1982) Generalized Method of Moments. Panels A, B, C and D present the values of $\rho$ that match respectively the variances, covariances, correlations and the entire variance-covariance matrix of observed returns and model-generated returns. Standard errors are in parentheses. The $\chi^{2}$ statistic is a test for the overidentifying restriction. General equilibrium values are obtained from (4) and partial ones are obtained from (3).

Point estimates of $\rho$ range from 1.4 to 15.7. When the full sample is used, the restrictions of the model are not rejected at the 5 per cent or 5 per cent significance level when either the variances or the cross-country covariances are used as moment equations under both the general and the partial equilibrium versions of the integrated model. However, the general equilibrium version is rejected when correlations are considered and both specifications fail when both variances and covariances are the moments to be matched. This, therefore, suggests again that while cross-country comovements of asset returns can be justified by an intertemporal model with fully integrated capital markets for a reasonable specification of pref- 
Table 5: Correlation of Generated Returns by a Unified Market Model (Matching Variances)

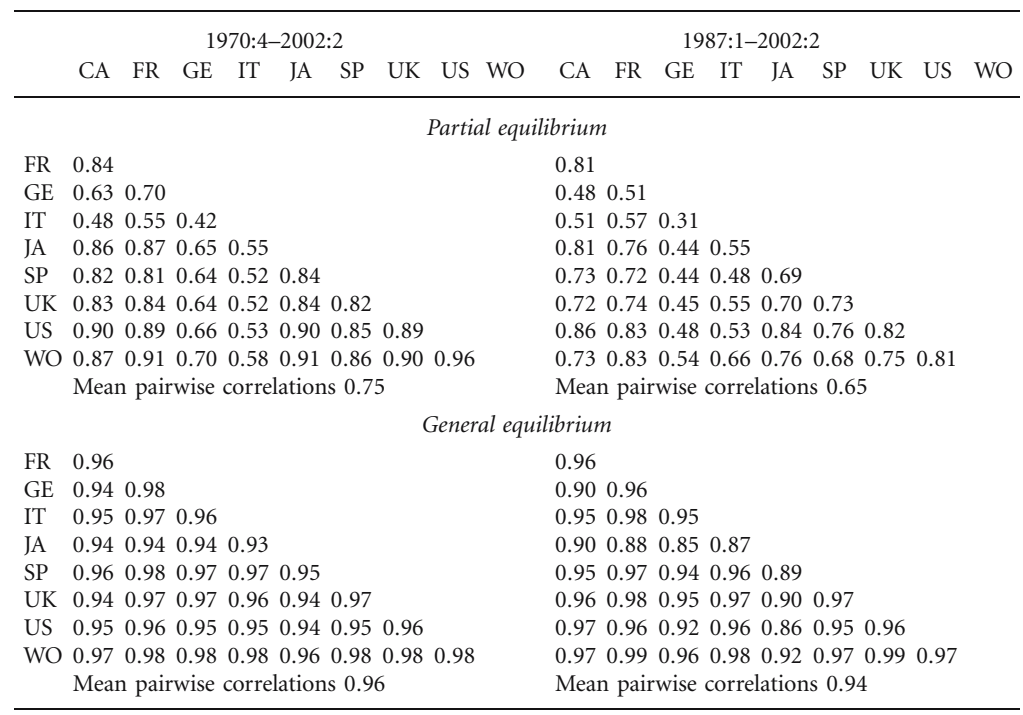

Note: This table gives the unconditional correlation matrices of national generated returns by perfectly integrated capital market models.

erences, that specification provides too little variability to domestic asset returns.

Table 5 provides an additional illustration of above results by looking at the cross-country correlation of model-generated returns. Not surprisingly, when variances of domestic returns are employed to estimate $\rho$, the resulting point estimate is too high to explain cross-country correlations. For high values of $\rho$, the common component of domestic returns (the pricing kernel) becomes dominant and induces too high cross-country correlations. This overestimation of co-movements is, however, less significant when dividends and not domestic output are used as the relevant payoffs. The reason is that dividends are, in general, less correlated across countries.

Results for the 1987-2002 subperiod are, as expected, much more favourable for the models. Only the general equilibrium specification when the variance-covariance matrix is used to match returns is rejected at the 5 per cent level, and the estimates of the inverse of the elasticity of intertem- 
poral substitution are all reasonable and significant. The partial equilibrium version of the model works considerably better than the one which imposes equality between dividends and output. Indeed, in the partial equilibrium case, the model fits satisfactorily both domestic asset return volatility and the cross-country co-variability for a single specification of preferences.

\section{Conclusions}

In this paper we have studied the ability of intertemporal asset pricing models to explain cross-country correlations of national returns.

Segmented capital market models, where returns of each country are generated only by domestic factors, are not consistent with the empirical evidence as correlations of model-generated returns are lower than the correlations of fundamentals. Intertemporal general equilibrium models with perfectly integrated capital markets are able to explain the obtained co-variability of domestic asset returns but generate too little variability in those returns.

We show that the performance of an integrated model improves considerably if a less restrictive (partial equilibrium) version is employed which does not assume that domestic dividends are equal to domestic output. Moreover, the performance also improves if the analysis is restricted to the last two decades which are characterized by a high degree of capital market liberalization.

\section{References}

Ammer, J., and J. Mei (1996). Measuring International Economic Linkages with Stock Market Data. Journal of Finance 51 (5): 1743-1763.

Campbell, J. Y. (1993). Intertemporal Asset Pricing without Consumption Data. American Economic Review 83 (3): 487-512.

Campbell, J. Y. (2000). Asset Pricing at the Millennium. Journal of Finance 55 (4): 1515-1567.

Campbell, J. Y., and R. J. Shiller (1988). The Dividend-Price Ratio and Expectations of Future Dividends and Discount Factors. Review of Financial Studies 1

(3): 195-228.

Cochrane, J. (2000). New Facts in Finance. Economic Perspectives. Federal Reserve Bank of Chicago. 
Cooper, I., and E. Kaplanis (1994). Home Bias in Equity Portfolios, Inflation Hedging, and International Capital Market Equilibrium. Review of Financial Studies 7 (1): 45-60.

Dumas, B., C. Harvey, and P. Ruiz (2003). Are Correlations of Stock Returns Justified by Subsequent Changes in National Outputs? Journal of International Money and Finance 22 (6): 777-811.

Epstein, L. G., and S. E. Zin (1989). Substitution, Risk Aversion, and the Temporal Behaviour of Consumption and Asset Returns: A Theoretical Framework. Econometrica 57 (4): 937-970.

French, K. R., and J. M. Poterba (1991). Investor Diversification and International Equity Markets. American Economic Review 81 (2): 222-226.

Hansen, L. P. (1982). Large Sample Properties of Generalized Method of Moments Estimators. Econometrica 50 (4): 1029-1054.

Restoy, F., and P. Weil (1998). Approximate Equilibrium Asset Prices. NBER Working Paper 6611. National Bureau of Economic Research, Cambridge, Mass.

Rodríguez, R., F. Restoy, and J. I. Peña (2002). Can Output Explain the Predictability and Volatility of Stock Returns. Journal of International Money and Finance 21 (2): 163-182.

Schwarz, G. (1978). Estimating the Dimension of a Model. The Annals of Statistics 6: 461-464.

Tesar, L., and I. M. Werner (1995). Home Bias and High Turnover. Journal of International Money and Finance 14 (4): 467-493.

Weil, P. (1989). The Equity Premium Puzzle and the Risk-Free Rate Puzzle. Journal of Monetary Economics 24 (3): 401-422. 